\title{
Life cycle of Amblyomma mixtum (Acari: Ixodidae) parasitizing different hosts under laboratory conditions
}

\author{
Francisco Tobias Barradas Piña ${ }^{1,2,7} \cdot$ Vinicius da Silva Rodrigues ${ }^{1,2}$ • \\ Leandro de Oliveira Souza Higa ${ }^{1,2}$ - Marcos Valério Garcia ${ }^{3,4}$. \\ Jacqueline Cavalcante Barros ${ }^{5}$ Adalberto Angel Pérez de León ${ }^{6}$. \\ Renato Andreotti ${ }^{5}$ (D)
}

Received: 29 June 2017/Accepted: 5 September 2017/Published online: 9 September 2017

(C) Springer International Publishing AG 2017

\begin{abstract}
Amblyomma mixtum is a tick species in the Amblyomma cajennense complex. The known geographic range of A. mixtum extends from Texas in the USA to western Ecuador and some islands in the Caribbean. Amblyomma mixtum is a vector of disease agents of veterinary and public health importance. The objective of this study was to describe the life cycle of A. mixtum under laboratory conditions. Bovines, rabbits and sheep were infested with larvae, nymphs, and adult ticks under controlled conditions to assess several biological parameters. Eggs, larvae, nymphs and adults were kept in an incubator $\left(27{ }^{\circ} \mathrm{C}\right.$ temperature
\end{abstract}

Renato Andreotti

renato.andreotti@embrapa.br

Francisco Tobias Barradas Piña

fcobarradast@gmail.com

Vinicius da Silva Rodrigues

vinicius_srod@hotmail.com

Leandro de Oliveira Souza Higa

leandro-higa@hotmail.com

Marcos Valério Garcia

marcosvagar@gmail.com

Jacqueline Cavalcante Barros

jacqueline.barros@embrapa.br

Adalberto Angel Pérez de León

beto.perezdeleon@ars.usda.gov

1 Pós-Graduação em Doenças Infecciosas e Parasitárias - Faculdade de Medicina, UFMS -

Universidade Federal Mato Grosso do Sul, Campo Grande, MS, Brazil

2 Laboratório de Biologia do Carrapato, Embrapa Gado de Corte, Campo Grande, MS, Brazil

3 Laboratório de Biologia do Carrapato, Empresa Brasileira de Pesquisa Agropecuária, Embrapa Gado de Corte, Campo Grande, MS, Brazil

4 Bolsista DCR Fundect, MS - Governo do estado de Mato Grosso do Sul, Campo Grande, Brazil

5 Empresa Brasileira de Pesquisa Agropecuária, Embrapa Gado de Corte, Avenida Rádio Maia, 830,

Campo Grande, MS CEP 79106-550, Brazil 
and $80 \%$ relative humidity) when they were off the host. The average life cycle of A. mixtum was 88 and 79 days when fed on rabbits and cattle, respectively. Sheep were found to be unsuitable because no ticks attached. The rabbit is a more practical host to maintain a colony of A. mixtum under laboratory conditions. The data from this study can be considered as an example for the life cycle of A. mixtum. However, caution must be exercised when making comparisons to the biology of $A$. mixtum in its natural habitat.

Keywords Bovine $\cdot$ Rabbit · Laboratory colony $\cdot$ Host suitability $\cdot$ Life cycle

\section{Introduction}

Ticks and tick-borne diseases affect humans and animals. Of the approximately 900 extant tick species described worldwide, those in the Ixodidae are the most diverse, comprising approximately 692 species (Nava et al. 2009; Sonenshine and Roe 2014).

Several species in the genus Amblyomma, one of 12 genera in the Ixodidae, are of veterinary and public health importance (Labruna et al. 2009; Guzman-Cornejo et al. 2011), including Amblyomma mixtum (Nava et al. 2014), which has a three-host life cycle (parasitizing humans, livestock, and wildlife) and is a vector of disease agents (Parola et al. 2005; Castro et al. 2015).

Following the original description by Koch (1844) based on specimens from Mexico, A. mixtum was reinstated as a species in the A. cajennense complex that includes $A$. cajennense sensu stricto (s.s.), A. mixtum, Amblyomma tonelliae, Amblyomma interandinum, Amblyomma patinoi and Amblyomma sculptum (Nava et al. 2014). The geographic range of A. mixtum extends from Texas in the USA to western Ecuador and some islands in the Caribbean, including Cuba and Trinidad and Tobago (Estrada-Pena et al. 2014; Nava et al. 2014; Beck and Orozco 2015). In some parts of Mexico, A. mixtum is an economically important ectoparasite of cattle, second only to Rhipicephalus microplus (Guzman-Cornejo et al. 2011; Rodriguez-Vivas et al. 2014). Controlling A. mixtum infestations in livestock can be challenging because of its euryxenous parasitic habit (Rodriguez-Vivas et al. 2016).

The biology of A. mixtum is not yet fully understood. The availability of laboratory tick colonies facilitates the study of tick biology, vector competence, and control technologies (Bouchard and Wikel 2005). However, some of the challenges to establishing and maintaining tick colonies in the laboratory setting include a shortage of adequate facilities, difficulties in maintaining experimental conditions, and high costs (Allan 2014; Thangamani and Bente 2014).

The results of our study on the colonization and life cycle of A. mixtum under laboratory conditions are presented here. Because of the complex interactions at the tick-host interface and their influence on tick rearing (Bouchard and Wikel 2005; Gerardi et al. 2013; Allan 2014), three animal species were tested for host suitability under laboratory conditions. The findings are discussed in the context of available data for other laboratory colonies of species in the A. cajennense complex.

6 USDA-ARS, Knipling-Bushland U.S. Livestock Insects Research Laboratory, and Veterinary Pest Genomics Center, Kerrville, TX, USA

7 Instituto Nacional de Investigaciones Forestales Agricolas y Pecuarias INIFAP, Mexico City, Mexico 


\section{Materials and methods}

\section{Animal care and use}

All experimental procedures involving animals were conducted in accordance with the rules of the Brazilian National Council of Animal Experimentation (CONCEA). Animal research was approved by the Ethics Committee on Animal Use/CEUA at the Federal University of Mato Grosso do Sul, Campo Grande, MS, Brazil (protocol number 699/2015). In this study sheep, bovines and rabbits were used.

\section{Tick rearing facility}

The study was performed on the Embrapa Gado de Corte Experimental Farm $\left(20^{\circ} 25^{\prime} 03^{\prime \prime} \mathrm{S}\right.$, $54^{\circ} 42^{\prime} 20^{\prime \prime} \mathrm{W}$ ), Animal Health sector, municipality of Campo Grande, state of Mato Grosso do Sul, Brazil, between November 2014 and March 2016.

\section{Tick source and rearing}

Amblyomma mixtum engorged females were collected from naturally infested bovines at a farm in Medellin de Bravo, Veracruz, Mexico $\left(19^{\circ} 01^{\prime} 01.6^{\prime \prime} \mathrm{N}, 96^{\circ} 08^{\prime} 14.4^{\prime \prime} \mathrm{W}\right)$. Engorged female ticks were weighed using an analytical scale and housed in vials with perforated covers and maintained in B.O.D. incubators at $27{ }^{\circ} \mathrm{C}$ and $80 \%$ relative humidity and a photoperiod regimen 12:12 (light:darkenss). In addition, the other tick life stages (eggs, larvae, and nymphs) were maintained under the same laboratory conditions to collect offhost data. The species was morphologically identified in accordance with the taxonomic characteristics described by Nava et al. (2014).

\section{Hosts}

Bovines (Bos taurus), rabbits (Oryctolagus cuniculus), and sheep (Ovis aries) were tested for their suitability as hosts for A. mixtum under laboratory conditions because those vertebrate species were reported to be susceptible to natural infestation or suitable laboratory hosts for North American populations formerly referred to as A. cajennense (Cooley and Kohls 1944; Drummond and Whetstone 1975). Ten rabbits of the New Zealand breed, with no previous tick contact and without distinction of gender were used. The chambers were fixed with atoxic glue, according to Szabó et al. (1995). The animals were kept in individual cages with free access to food and water.

Three bovines (Bos taurus), ranging in age from 8 to 12 months were kept in individual stalls with free access to food and water. The animals, with previous tick contact, were not treated with acaricides for at least 30 days before infestation. Plastic chambers were used as described above in an area on the back of the animal where hair had been clipped to allow tick feeding. Care and use protocols for bovines were adapted for two adult Santa Ines sheep. These animals had previous contact with ticks. A plastic chamber was also glued to a shaved portion of the sheep's back to confine ticks and allow blood feeding. Santa Ines sheep were chosen because they are sensitive to infestation by ticks (Garcia et al. 2014). 


\section{Experimental infestations}

Approximately 1000 larvae, 90 nymphs and 12 adult ticks (six males and six females), were used per infestation and per animal. Ticks were placed in feeding chambers on the rabbits, cattle and sheep. All ticks used in experimental infestations were between 15 and 20 days in age. Tick fixation takes only a few minutes. Feed chambers were individually inspected daily to collect engorged ticks. All naturally detached engorged ticks from different hosts were removed from the chambers and taken to the laboratory where they were counted, weighed and identified in vials for incubation and maintained in B.O.D. incubators at $27{ }^{\circ} \mathrm{C}$ and $80 \%$ relative humidity, and a photoperiod regimen 12:12 (light:darkenss).

\section{Parameters analyzed}

Several biological parameters were assessed in larvae, nymphs, and engorged female ticks. The formulae described below were adapted and information from other studies was used to make relevant comparisons to A. cajennense sensu lato (s.1.) (Hooker et al. 1912; Drummond and Whetstone 1975; Szabó et al. 1995; Sanavria and Prata 1996; Gerardi et al. 2013). To calculate the biological parameters we performed a weighted average. The duration of the life cycle described by us is related only to feeding, molting, pre-oviposition and incubation, being discarded the period when unfed ticks were allowed to feed.

\section{Larval parameters}

The engorgement period was defined as the number of days from larvae infestation on the host until the collection day of detached larvae. To calculate the average duration of the engorgement period we performed a weighted average. The individual weight of engorged larvae was estimated from the total weight of larvae collected divided by the number of larvae collected. The duration of the molting process period was defined as the number of days from larvae detachment from the host until the premolt periods. The molting success was defined as the number of larvae that underwent metamorphosis divided by the number of engorged larvae that were collected multiplied by $100 \%$.

\section{Nymphal parameters}

The feeding success was defined as the number of nymphs collected divided by the number of released nymphs multiplied by $100 \%$.

The engorgement period was defined as the number of days from nymph infestation on the host until the collection day of released nymphs. To calculate the average duration of the engorgement period we performed a weighted average. The individual weight of engorged nymphs was defined as the total weight of nymphs collected divided by the number of nymphs collected. The duration of the molting process period was defined as the number of days from nymphs detachment from the host until the premolt periods. The molting success was defined as the number of engorged nymphs that underwent metamorphosis divided by the number of engorged nymphs collected, multiplied by $100 \%$. 


\section{Engorged female parameters}

The feeding success was defined as the number of engorged females that were collected divided by the number of released females multiplied by $100 \%$. The engorgement period was defined as the number of days from the release of adult ticks on the host until the detachment of engorged females. To calculate the average duration of the engorgement period we performed a weighted average. Engorged female weight was determined by weighing each adult female. The pre-oviposition period was defined as the number of days from detachment until the beginning of oviposition. Egg mass weight was defined as the total egg mass deposited by the engorged female. The egg incubation period was defined as the number of days from the beginning of oviposition until larvae eclosion. Larvae eclosion percentage was determined by visual estimation and calculated from the average obtained by three examiners (Szabó et al. 1995). The efficiency index of the conversion of food reserve into eggs was defined as egg mass weight divided by engorged female weight multiplied by $100 \%$.

Descriptive statistics were applied to summarize and describe the biological data. The life cycle parameters of $A$. mixtum obtained in the laboratory were analyzed using BioEstat 5.0 software, with Kruskal-Wallis and Mann-Whitney tests $(\alpha=0.05)$.

\section{Results}

Bovines and rabbits were more suitable than were sheep as hosts for A. mixtum under laboratory conditions. Sheep were found to be unsuitable because no ticks attached.

\section{Infestation on rabbits}

It took 88 days on average for A. mixtum to complete its life cycle when feeding on rabbits under laboratory conditions. Thus, approximately 4.1 generations/year could be produced under the laboratory conditions used in this study. Biological parameters obtained from larvae and nymphs were listed in Tables 1 and 2, respectively. The values of reproductive parameters for females are listed in Table 3.

Table 1 Mean ( \pm SD; range in parentheses) biological parameters of Amblyomma mixtum larvae feeding on rabbit or bovine hosts under laboratory conditions

\begin{tabular}{|c|c|c|c|c|}
\hline \multirow[t]{2}{*}{ Host } & \multirow[t]{2}{*}{ Weight (mg) } & \multicolumn{2}{|c|}{ Period (days) } & \multirow{2}{*}{$\begin{array}{l}\text { Percentage } \\
\text { Molting }\end{array}$} \\
\hline & & Feeding & Molting & \\
\hline Rabbit & $\begin{array}{l}0.73 \pm 0.6^{\mathrm{a}} \\
(0.65-0.78)\end{array}$ & $\begin{array}{l}6.3 \pm 2.4^{\mathrm{a}} \\
(3-12)\end{array}$ & $\begin{array}{l}12.6 \pm 2.3^{\mathrm{a}} \\
(9-17)\end{array}$ & $\begin{array}{l}74.6 \pm 16.3^{\mathrm{a}} \\
(60-96.8)\end{array}$ \\
\hline Bovine & $\begin{array}{l}0.96 \pm 0.3^{\mathrm{b}} \\
(0.77-1.41)\end{array}$ & $\begin{array}{l}5.5 \pm 1.2^{\mathrm{b}} \\
(4-7)\end{array}$ & $\begin{array}{l}11.5 \pm 1.2^{\mathrm{b}} \\
(10-13)\end{array}$ & $\begin{array}{l}90.5 \pm 6.9^{\mathrm{b}} \\
(80.4-96)\end{array}$ \\
\hline
\end{tabular}

Means within a column followed by different letters are significantly different $(p<0.05)$ 
Table 2 Mean ( \pm SD; range in parentheses) biological parameters of Amblyomma mixtum nymphs feeding on rabbit and bovine hosts under laboratory conditions

\begin{tabular}{|c|c|c|c|c|c|}
\hline \multirow[t]{2}{*}{ Host } & \multirow[t]{2}{*}{ Yield (\%) } & \multirow[t]{2}{*}{ Weight (mg) } & \multicolumn{2}{|c|}{ Period (days) } & \multirow{2}{*}{$\begin{array}{l}\text { Percentage } \\
\text { Molting }\end{array}$} \\
\hline & & & Feeding & Molting & \\
\hline Rabbit & $\begin{array}{l}65 \pm 28.2 \\
(27.8-92.9)\end{array}$ & $\begin{array}{l}12.8 \pm 2.7 \\
(9.1-15.2)\end{array}$ & $\begin{array}{l}7.45 \pm 2.9 \\
(3-13)\end{array}$ & $\begin{array}{l}13.5 \pm 2.3 \\
(9-17)\end{array}$ & $\begin{array}{l}92.7 \pm 14.5 \\
(71-100)\end{array}$ \\
\hline Bovine & $\begin{array}{l}43.3 \pm 49.3 \\
(10.3-100)\end{array}$ & $\begin{array}{l}15.6 \pm 1.7 \\
(13.7-17)\end{array}$ & $\begin{array}{l}6 \pm 2.5 \\
(4-10)\end{array}$ & $\begin{array}{l}12.6 \pm 2.4 \\
(10-16)\end{array}$ & $\begin{array}{l}92 \pm 10.5 \\
(80-100)\end{array}$ \\
\hline
\end{tabular}

\section{Infestation on cattle}

The average life time of $A$. mixtum using bovine hosts under laboratory conditions was 79 days. Thus, approximately 4.6 generations/year could be produced under the laboratory conditions used in this study. For larvae and nymphs, the mean values obtained were listed in Table 1 and Table 2, respectively. The values of reproductive parameters for females are listed in Table 3.

\section{Discussion}

This is the first study to report data on the life cycle of A. mixtum under laboratory conditions on three different hosts. This tick species was originally described by Koch (1844) and was reinstated by Nava et al. (2014). Ticks in the genus Amblyomma are represented by 26 species in Mexico, and A. mixtum is one of the most widely distributed and prevalent species parasitizing livestock, wildlife and humans (Guzman-Cornejo et al. 2011; Rodriguez-Vivas et al. 2016).

The study of $A$. mixtum as a member of the A. cajennense complex is important because previous information related to A. mixtum in North America was reported under the $A$. cajennense specific name, including data for colonies maintained in several North American laboratories that did not highlight the potential variations between the six species that are part of the complex (Hooker et al. 1912; Cooley and Kohls 1944; Drummond and Whetstone 1975).

Cattle and sheep can be naturally infested with A. cajennense s.l. (Guglielmone and Nava 2006; Alvarez and Bonilla 2007; Gonzalez-Ceron et al. 2009; Ramos et al. 2016). Rabbits are small laboratory animals that are commonly used to maintain colonies of ticks (Sanavria and Prata 1996). The laboratory results presented here confirm field observations suggesting that A. mixtum is a generalist host. Based on our findings, rabbits may be the preferred species for long-term maintenance of A. mixtum colonies because of their small size, which makes them relatively easier to handle and more convenient with regard to the laboratory facilities required for housing and husbandry costs. And also because all instars of this tick specie had satisfactory results when submitted to feeding on rabbits.

According to the results of this study, the life cycle of A. mixtum under laboratory conditions was 88 days when infested on rabbits and 79 days when infested on cattle, unlike that presented by Almazán et al. (2016), this authors reported a life cycle for this species of tick from 133 to 193 days. For pre-oviposition, the present study reports a 


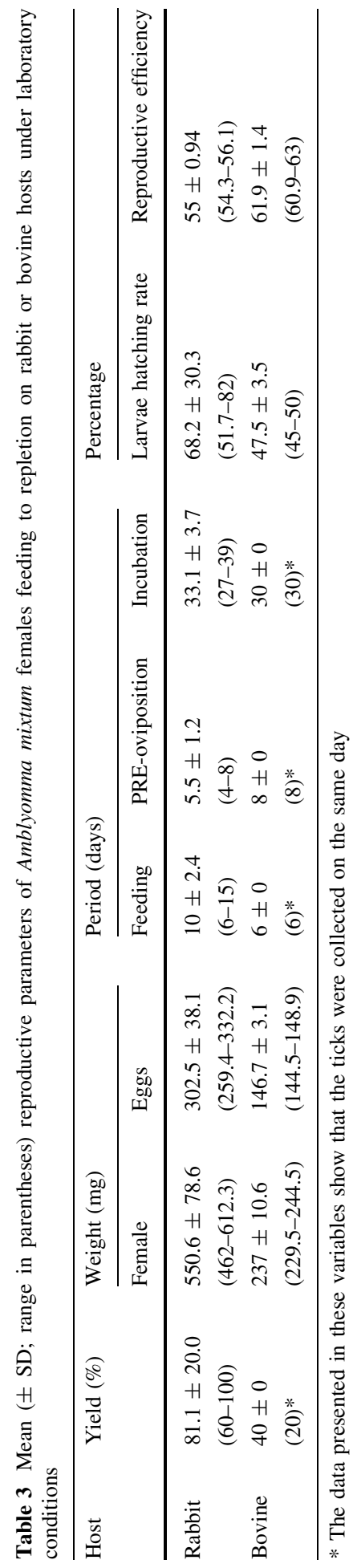


significantly shorter period than those obtained by Almazán et al. (2016), which showed a variation of 25-29 days for the same parameter, with the cattle as hosts.

Under the same conditions of the present study Almazán et al. (2016) reported an incubation period similar to the results presented by us, as well as a similarity in the engorgement time of all instars of this species of tick in both studies. However different values were reported for the duration of the molting process of nymphs and adults, in which these authors obtained a greater period for this parameter.

In relation to the weight of engorged ticks recovered as well as the respective masses of eggs obtained, the values presented here are significantly lower than those obtained by Almazán et al. (2016). However, the food conversion rate of A. mixtum in the present study has a difference of $8.6 \%$ more compared to Almazán et al. (2016).

The hypotheses for the differences between the parameters analyzed between larvae, nymphs and adults in the present work in comparison to the results obtained by Almazán et al. (2016) can be several factors, such as, management condition, different breeds of cattle used as hosts, climatic conditions of the study sites and, season of the year.

Our results were similar to those reported for A. mixtum (reported as A. cajennense) in Texas (Hooker et al. 1912; Strickland et al. 1976). Nymphs of what is now A. mixtum from Texas took 3-13 days to engorgement (Strickland et al. 1976), whereas, in our study, nymphs completed feeding after 4-10 days on cattle, and 3-13 days on rabbits.

The acquisition of data for the life cycle of A. mixtum under laboratory conditions provided an opportunity for comparative analyses with other tick species of the Amblyomma cajennense complex and other Amblyomma species under laboratory conditions.

Considering the data reported by Tarragona et al. (2015), A. tonelliae under laboratory conditions, when evaluated in different photoperiods before and after feeding, presented a pre-oviposition period of 7-17 days when rabbits were used as hosts. For the A. mixtum infesting the same host species, in the present study, the pre-oviposition period varied from 4 to 8 days.

Amblyomma tonelliae engorged female weight varied from 291 to $791 \mathrm{mg}$, while the $A$. mixtum engorged female weight when infesting rabbits varied from 462 to $612.3 \mathrm{mg}$, while when infesting bovines varied from 229.5 to $244.5 \mathrm{mg}$. The incubation period for $A$. tonelliae varied from 36 to 45 days, and for A. mixtum varied from 27 to 39 days when infesting rabbits.

Lisboa et al. (1998) reported that A. sculptum larvae feeding on rabbits required three to seven days to engorgement. Prata et al. (1996), in a study with A. sculptum nymphs feeding on rabbits, reported a recovery rate of $53.4 \%$ for nymphs, an engorgement period of 5 days, and a $95 \%$ molting success. Similar values to the results found in this study with A. mixtum.

Regarding the adult ticks, yield values and reproductive efficiencyfor A. mixtum were similar to the values reported for other tick species from genre Amblyomma under laboratory conditions (Troughton and Levin 2007; Olegario et al. 2011; Faccini et al. 2010; Labruna et al. 2004).

Comparisons of biological parameters across the life stages of Amblyomma reared in the laboratory show the complex adaptations associated with a three-host life cycle, which may be affected by biotic and abiotic factors (Szabó et al. 2009).

The colony of $A$. mixtum provides an opportunity to produce a continuous supply of ticks for further research on their biology, role as a vector of disease agents, and control technologies. This is especially important in parts of North America where A. mixtum is a vector of veterinary and public health importance, including Mexico, where laboratory colonies are not available (Gonzalez-Ceron et al. 2009; Illoldi-Rangel et al. 2012; AlonsoDiaz et al. 2013). 
Significant differences have been reported in biological parameters between conspecific ticks under field conditions and those reared in the laboratory (Yu et al. 2010; Meng et al. 2014). The results showed that rabbits and bovines can be a host to maintain this tick species in laboratory, the data from this study conducted under laboratory conditions can be considered as an example for the life cycle of A. mixtum. However, caution must be exercised when making comparisons to the biology of $A$. mixtum in its natural habitat.

Acknowledgements To the Coordenação de Aperfeiçoamento de Pessoal de Nível Superior (Capes), Conselho Nacional de Desenvolvimento Científico e Tecnológico (CNPq), Fundação de Apoio ao Desenvolvimento do Ensino, Ciência e Tecnologia do Estado de Mato Grosso do Sul (Fundect, MS) - Governo do Estado de Mato Grosso do Sul, Embrapa Gado de Corte, Instituto Nacional de Investigaciones Forestales Agricolas y Pecuarias (INIFAP-Mexico), and Consejo Nacional de Ciencia y Tecnologia (CONACyT) for financial support of the project, USDA is an equal opportunity provider and employer.

\section{Compliance with ethical standards}

Conflict of interests The authors declare to have no conflict of interest.

\section{References}

Allan SA (2014) Tick rearing and in vitro feeding. In: Sonenshine DE, Roe RM (eds) Biology of ticks, 2nd edn. Oxford University Press, New York, pp 445-473. ISBN 978-0-19-974450-3

Almazán C, Torres-Torres A, Torres-Rodriguez L, Soberanes-Cespedes N, Ortiz-Estrada M (2016) Aspectos biologicos de Amblyomma mixtum (Koch, 1844) en el noreste de Mexico. Queh Cient Chiapas 11:10-19

Alonso-Diaz MA, Fernandez-Salas A, Martinez-Ibanez F, Osorio-Miranda J (2013) Amblyomma cajennense (Acari: Ixodidae) tick populations susceptible or resistant to acaricides in the Mexican Tropics. Vet Parasitol 197:326-331. doi:10.1016/j.vetpar.2013.06.004

Alvarez CV, Bonilla MR (2007) Adultos y ninfas de la garrapata Amblyomma cajennense Fabricius (Acari: Ixodidae) en equinos y bovinos. Agron Costarric 31:61-69

Beck DL, Orozco JP (2015) Diurnal questing behavior of Amblyomma mixtum (Acari: Ixodidae). Exp Appl Acarol 66:613-621. doi:10.1007/s10493-015-9928-X

Bouchard K, Wikel S (2005) Care, maintenance and experimental infestation of ticks in the laboratory setting. Biol Dis Vectors 2:705-712

Castro DAM, Garcia SGG, Dzul-Rosado K, Aguilar A, Castillo J, Gabster A, Trejos D, Zavala-Castro J, Bermúdez SEC (2015) Questing Amblyomma mixtum and Haemaphysalis juxtakochi (Acari: Ixodidae) infected with candidatus "Rickettsia amblyommii" from the natural environment in Panama Canal Basin, Panama. Trop Med Health 43:217-222. doi:10.2149/tmh.2015-07

Cooley RA, Kohls GM (1944) The genus Amblyomma (Ixodidae) in the United States. J Parasitol 30:77-111. doi: $10.2307 / 3272571$

Drummond RO, Whetstone TM (1975) Oviposition of the cayenne tick, Amblyomma cajennense (F.), in the laboratory. Ann Entomol Soc Am 68:214-216. doi:10.1093/aesa/68.2.214

Estrada-Pena A, Tarragona EL, Vesco U, Meneghi D, Mastropaolo M, Mangold AJ, Guglielmone AA, Nava S (2014) Divergent environmental preferences and areas of sympatry of tick species in the Amblyomma cajennense complex (Ixodidae). Int J Parasitol 44:1081-1809. doi:10.1016/j.ijpara.2014.08.007

Faccini JLH, Cristina BA, Onofrio CVC, Labruna MB, Barros-Battesti DM (2010) The life cycle of Amblyomma auricularium (Acari: Ixodidae) using rabbits (Oryctolagus cuniculus) as experimental host. Exp Appl Acarol 50:71-77. doi:10.1007/s10493-009-9281-z

Garcia MV, Andreotti R, Reis FA, Aguirre AAR, Barros JC, Matias J, Koller WW (2014) Contributions of the hair sheep breed Santa Ines as a maintenance host for Rhipicephalus (Boophilus) microplus (Acari: Ixodidae) in Brazil. Parasites Vectors 7:1-4. doi:10.1186/s13071-014-0515-5

Gerardi M, Martins MM, Nava S, Szabo MPJ (2013) Comparing feeding and reproductive parameters of Amblyomma parvum tick populations (Acari: Ixodidae) from Brazil and Argentina on various host species. Vet Parasitol 197:312-317. doi:10.1016/j.vetpar.2013.06.018

Gonzalez-Ceron F, Becerril-Perez CM, Torres-Hernandez G, Diaz-Rivera P (2009) Ticks infesting body regions of tropical milking criollo cattle in Veracruz, Mexico. Agrociencia 43:11-19 
Guglielmone AA, Nava S (2006) Las Garrapatas Argentinas del Genero Amblyomma (Acari: Ixodidae): Distribucion y hospedadores. RIA 35:133-153

Guzman-Cornejo C, Robbins RG, Guglielmone AA, Montiel-Parra G, Perez TM (2011) The Amblyomma (Acari: Ixodida: Ixodidae) of Mexico: Identification keys, distribution and hosts. Zootaxa 2998:16-38

Hooker WA, Bishopp FC, Wood HP (1912) The life history and bionomics of some North American ticks. Bur Entomol Bull 106:72-87

Illoldi-Rangel P, Rivaldi CL, Sissel B, Fryxell RT, Gordillo-Perez G, Rodriguez-Moreno A, Montiel-Parra P, Sánchez-Cordero V, Sarkar S (2012) Species distribution models and ecological suitability analysis for potential tick vectors of lyme disease in Mexico. J Trop Med 2012:1-10. doi:10.1155/2012/959101

Koch CL (1844) Systematische Übersicht über die ordnung der zecken. Arch Naturg 10:217-239

Labruna MB, Pinter A, Teixeira RHF (2004) Life cycle of Amblyomma cooperi (Acari: Ixodidae) using capybaras (Hydrochoerus hydrochaeris) as hosts. Exp Appl Acarol 32:79-88. doi:10.1023/B:APPA. 0000018228.05088 .26

Labruna MB, Terassini FA, Camargo LM (2009) Notes on population dynamics of Amblyomma ticks (Acari: Ixodidae) in Brazil. J Parasitol 95:1016-1018. doi:10.1645/GE-1878.1

Lisboa CML, Leite RC, Labruna MB, Oliveira PR, Borges LMF, Rodrigues ZB, Carvalho HA, Freitas CMV, Júnior CRV (1998) Host specificity of Amblyomma cajennense (Fabricius, 1787) (Acari: Ixodidae) with comments on the drop-off rhythm. Mem Inst Oswaldo Cruz 93:347-351. doi:10.1590/ S0074-02761998000300014

Meng H, Xu S, Yu Z, Liu Z, Liu J, Yang X, Liu J (2014) The life cycle and occurrence of Haemaphysalis concinna (Acari: Ixodidae) under field conditions. Ticks Tick Borne Dis 5:887-891. doi:10.1016/j. ttbdis.2014.07.007

Nava S, Guglielmone AA, Mangold AJ (2009) An overview of systematics and evolution of ticks. Front Biosci 14:2857-2877. doi:10.2735/3418

Nava S, Beati L, Labruna MB, Caceres AG, Mangold AJ, Guglielmone AA (2014) Reassessment of the taxonomic status of Amblyomma cajennense (Fabricius, 1787) with the description of three new species, Amblyomma tonelliae n. sp., Amblyomma interandinum n. sp. and Amblyomma patinoi $\mathrm{n}$. sp., and reinstatement of Amblyomma mixtum Koch, 1844, and Amblyomma sculptum Berlese, 1888 (Ixodida: Ixodidae). Ticks Tick Borne Dis 5:252-276. doi:10.1016/j.ttbdis.2013.11.004

Olegario MMM, Gerardi M, Tsuruta SA, Szabo MPJ (2011) Life cycle of the tick Amblyomma parvum Aragao, 1908 (Acari: Ixodidae) and suitability of domestic hosts under laboratory conditions. Vet Parasitol 179:203-208. doi:10.1016/j.vetpar.2011.01.056

Parola P, Christopher D, Paddock CD, Raoult D (2005) Tick-borne rickettsioses around the world: emerging diseases challenging old concepts. Clin Microbiol Rev 18:719-756

Prata AMC, da Silva LA, Sanavria A (1996) Parâmetros biológicos do estagio ninfal de Amblyomma cajennense (Fabricius, 1787) (Acari: 1xodidae) em coelhos. Rev Bras Ciênc Vet 3:55-57. doi:10.4322/ rbcv.2015.045

Ramos VN, Piovezan U, Franco AHA, Rodrigues VS, Nava S, Szabo MPJ (2016) Nellore cattle (Bos indicus) and ticks within the Brazilian Pantanal: ecological relationships. Exp Appl Acarol 68:227-240. doi:10.1007/s10493-015-9991-3

Rodriguez-Vivas RI, Perez-Cogollo LC, Rosado-Aguilar JA, Ojeda-Chi MM, Trinidad-Martinez T, Miller JR, Li AY, de León AP, Guerrero F, Klafke G (2014) Rhipicephalus (Boophilus) microplus resistant to acaricides and ivermectin in cattle farms of Mexico. Braz J Vet Parasitol 23:113-122. doi:10.1590/ S1984-29612014044

Rodriguez-Vivas RI, Apanaskevich DA, Ojeda-Chi MM, Trinidad-Martinez I, Reyes-Novelo E, EsteveGassent MD, de León AAP (2016) Ticks collected from humans, domestic animals, and wildlife in Yucatan, Mexico. Vet Parasitol 215:106-113. doi:10.1016/j.vetpar.2015.11.010

Sanavria A, Prata MCA (1996) Metodologia para colonização do Amblyomma cajenennse (Fabricius, 1787) (Acari:Ixodidae) em laboratório. Rev Bras Parasitol Vet 5:87-90

Sonenshine DE, Roe RM (2014) Biology of ticks, 2nd edn. Oxford University Press, Oxford. ISBN 978-019-974405-3

Strickland RK, Gerrish RR, Hourrigan JL, Schubert GO (1976) Ticks of veterinary importance. U.S. Government Printing Office, Washington

Szabó MPJ, Mukay LS, Rosa PCS, Bechara GH (1995) Differences in the acquired resistance of dogs, hamsters and guinea pigs to repeated infestations with adults ticks Rhipicephalus sanguineus (Acari:Ixodidae). Braz J Res Anim Sci 32:43-50. doi:10.11606/issn.0000-0000.32143-50

Szabó MPJ, Pereira LF, Castro MB, Garcia MV, Sanches GS, Labruna MB (2009) Biology and life cycle of Amblyomma incisum (Acari: Ixodidae). Exp Appl Acarol 48:263-271. doi:10.1007/s10493-008-9234-y

Tarragona EL, Mangold AJ, Mastropaolo M, Guglielmone AA, Nava S (2015) Ecology and genetic variation of Amblyomma tonelliae in Argentina. Med Vet Entomol 29:297-304. doi:10.1111/mve.12110 
Thangamani S, Bente D (2014) Establishing protocols for tick containment at biosafety level 4. Pathog Dis 71:282-285. doi:10.1111/2049-632X.12187

Troughton DR, Levin ML (2007) Life cycles of seven Ixodid tick species (Acari: Ixodidae) under standardized laboratory conditions. J Med Entomol 44:732-740. doi:10.1093/jmedent/44.5.732

Yu Z, Zheng H, Chen Z, Zheng B, Ma H, Liu J (2010) The life cycle and biological characteristics of Dermacentor silvarum Olenev (Acari: Ixodidae) under field conditions. Vet Parasitol 168:323-328. doi:10.1016/j.vetpar.2009.11.010 